\title{
Sydney Airport Land: Appropriate Value for Regulatory Purposes
}

\section{Rohan Pitchford and Andrew Wait}

$\mathrm{L}$ anding charges and other fees at Sydney's Kingsford Smith airport for regional air services are regulated by price caps. The Australian Competition and Consumer Commission (ACCC) is charged with recommending approval or denial of requests for revisions of these caps. The method by which price caps are revised is therefore important, both for the efficiency with which services are delivered to users and for the return enjoyed by investors in the airport. Currently, price caps are supposed to be calculated so that a reasonable rate of return is made on the set of airport assets. Since land potentially makes up a significant component of the value of the Airport's asset base (Productivity Commission, 2002:401-02), the method by which Sydney Airport land is valued is crucial. Land valuation methodology - for the purpose of regulation - is the topic of this paper.

One suggestion is to use surrounding land value as an approximation. Prior to privatisation, as part of its negotiations with the ACCC over price cap revisions, Sydney Airport Corporation Ltd (SACL) hired the distinguished economist Professor Alfred Kahn, who generally supported SACL's argument that surrounding land value is an appropriate measure for the purposes of regulating Sydney Airport. In his evidence, Professor Kahn (2001:4) asserted:

My airline clients and I maintained that the only possible basis of independent valuation (free of the circularity I described), and in any event its true economic cost, was its opportunity cost (its value in the next most valuable use) ... . I know of no economist who would disagree with that proposition, and the Sydney Airports Corporation explicitly adopts it here. (brackets and some punctuation added)

The Productivity Commission (2002:410) weighed into the debate by arguing that valuing airport land at its surrounding value, for the purpose of regulation, would assist the government with decisions concerning the location of the airport.

We will describe the proposition that surrounding land value is the appropriate measure as the 'ambient value' argument. In this paper we suggest an alternative method of valuing airport land. In fact, our analysis lends support for the ACCC's CPI-adjusted historic cost valuation, as opposed to the ambient-value approach advocated above by SACL and the Productivity Commission. The

Rohan Pitchford is a Professor of Economics in the Discipline of Economics, The University of Sydney and Andrew Wait is a Lecturer in the Discipline of Economics, The University of Sydney. 
difference between the proposed approaches is significant - the ACCC's valuation of Sydney Airport land was $\$ 452 \mathrm{~m}$, compared with the SACL's estimate of $\$ 705 \mathrm{~m}$ (ACCC 2001:16). This revaluation alone led to average aeronautical charges being 8 per cent lower than under SACL's estimate (Productivity Commission, 2002:402).

In a nutshell, our argument is as follows. The airport land, for the most part, is sunk in its current use - that is, the land cannot be sold and used for another purpose. A second assumption, also crucial to our argument, is that airport land is not always fully utilised. (We discuss this in greater detail below, but it follows directly from the airport having peak and non-peak periods of demand.) As long as the airport cannot be moved, and capacity is sometimes idle, the appropriate value for regulatory purposes, of land sunk in airport use, can be determined with reference to the original price of the land and the growth in demand for airport services since that time, and is not simply equated with ambient value. The ambient value is only the correct measure if airport capacity is always fully utilised, and such capacity is chosen to maximise social surplus.

Two facts about the airport are crucial for the model we develop below. First, Sydney Airport's original location was chosen, and capacity added over the years, when the price of land was low. This point is important, because the amount of land purchased in the past would undoubtedly be larger than if the purchase were to be made today. Indeed, it could be argued that if the airport was built again from scratch it would be located elsewhere, due to this expense. Second, as mentioned, a significant part of land is sunk in airport uses. In the basic model we make the simplifying assumption that all of the land is unconvertible (note: the basic reasoning is unaffected by land at the fringes being able to be sold). We demonstrate that these two assumptions imply the (marginal) value of the land of 'yesterday's size airport' over 'today's desired size airport' lies below the current market price (that is, the ambient value) of land, even in the situation where the airport is significantly transformed by modern capital inputs.

We also consider several other extensions. For example, we allow the airport builders to fully anticipate future land prices and airport use. We find that the ambient value continues to overstate the true value of the land (with similar implications for regulated price caps), although this change means that the ambient value is used as part of the calculation of the true value. We also show that the presence of externalities between airport and other land uses do not affect the basic premise of our argument. A discussion of some of the issues that arise from the model and the conclusion complete the body of the paper. The formal model underlying the analysis is presented in the appendix.

\section{The Basic Model}

The following model is made deliberately simple only for expositional purposes. The arguments generalise very easily to more complex environments. For the purposes of the model we will assume that the airport was initially publicly owned and that the publicly-owned airport had the objective of maximising the net 
surplus generated by the land from the airport's use (to be defined more specifically below). The relevant question today concerns the land valuation for the purposes of price regulation of the now privately operated airport. We help answer this question by considering what a social surplus-maximising airport operator should do. In particular, we consider the socially optimal size of the airport if it were to be established today and the implications this has for airport land valuation for the purpose of price regulation. Of course, a publicly-owned airport or regulator could pursue other objectives. This objective has been chosen as it is the most appropriate in helping the regulator (the ACCC) assess land values in setting regional price caps. A discussion of other possible objectives is included in the discussion section below.

Consider an airport that only requires land as an input, although the argument extends very simply to many inputs such as capital and labour. Let $\mathrm{L}_{0}$ denote the amount of land used by the airport at 'time 0 ' when the airport was substantively established, and $\mathrm{L}_{1}$ be the socially optimal amount of land today - at 'time 1'. Suppose that the price of land at time 0 was $\mathrm{p}_{0}$ and the price of land today is $\mathrm{p}_{1}$. The benefit delivered by the airport in each period depends on how much land is allocated to its use. For simplicity assume that there is a declining marginal benefit from each additional unit of land used for airport service - in other words, there is a downward sloping demand curve for airport land. A social planner, with the objective of maximising net benefit of airport use, will consider the potential benefits generated by alternative uses of the land. Provided there is a competitive market for land, these potential benefits - the willingness to pay of alternative users - are reflected in the price of land. Choosing the optimal airport size will require a comparison of the benefit of land to airport users and its price.

Assume that the public-owned airport at time 0 was built under a myopic objective to maximise the net value to users of the airport based on price $\mathrm{p}_{0}$; note that as $p_{0}$ reflects the benefits of the land to other users, maximising the net benefit to airport users will maximise total surplus. Moreover, when we discuss extensions of the argument, we will show that our analysis does not hinge on the assumption of a myopic planner. In this case the social planner will choose the size of the land input $\mathrm{L}_{0}$ so that the marginal benefit of the land is equal to its marginal cost (the price of land $\mathrm{p}_{0}$ ).

The fact that there is a substantial sunk or unconvertible component of land, regardless of its source, is crucial to our argument that ambient value is not likely to be the correct measure (see, for example, Forsyth (1997:298). This irreversibility arises for several reasons. First, once aeroplane manoeuvring space (called 'aprons'), runways and buildings have been installed on the land, substantial reversal of land usage is essentially impractical. Second, now that it has been established, converting the airport is disallowed by regulation or legislation - given the terms of its purchase agreement, the SACL is not free to shut the airport and establish another business on the site or sell all of the land. Such a ban is due to the substantial quantity of related investments in and outside the airport - in such things as transport infrastructure, worker location and airport-supporting business - that have been made as a result of the airport's 
location (see ACCC, 2001:135-36). It is, of course, inconceivable that the Federal government would allow the airport to be shut, or substantially altered in a way that reduces its capacity.

For the purpose of argument, now suppose that $\mathrm{L}_{0}$ cannot be reduced for reasons argued above; that is, the whole of the land is sunk or unconvertible. Relaxing this assumption is not crucial. What is crucial is that there is a substantial fraction of $\mathrm{L}_{0}$ that is sunk in its existing use.

At time 1, the airport regulator wishes to assess the value of the airport land for purposes of regulation. Should it be valued at $\mathrm{p}_{1} \cdot \mathrm{L}_{1}$ - the surrounding land value - or some other value? Were the airport built today, the public owners would compare the current land price $\mathrm{p}_{1}$ with the benefits derived from using the land to generate airport services. The airport owners would either: opt for an airport of size $\mathrm{L}_{1}$, which ensures that the marginal benefit of the last unit of airport land is equal to the marginal cost of land $\left(\mathrm{p}_{1}\right)$; or choose to locate the airport elsewhere if the land price is too high relative to the benefits (that is, set $\mathrm{L}_{1}=0$ ).

Let us compare the airport's size if it were built at time $0\left(\mathrm{~L}_{0}\right)$ with its size if it were to be built today $\left(\mathrm{L}_{1}\right)$. If the growth in surrounding land value is sufficiently high relative to the growth in demand for airport services, then the amount of land that would be devoted to an airport on this site - were it built today - would be smaller than the size originally allocated. As mentioned, some argue that $\mathrm{L}_{1}=0$ would be chosen if the whole process was done over, and that the airport would be located elsewhere, on cheaper land. A formal model of these arguments is presented in the Appendix (see Proposition 1).

Now we are in a position to consider the appropriate valuation of airport land for the purposes of regulation. As the airport size is fixed, the marginal value of land at time 1 is evaluated using today's demand for airport services at $\mathrm{L}_{0}$. If we accept that the airport established previously is larger than the size that would have been chosen today (that is, $\mathrm{L}_{1}<\mathrm{L}_{0}$ ) because the demand for airport services is downward sloping, the marginal benefit of airport land today will be less than the current land price $p_{1}$. In other words, the ambient value argument is incorrect. Indeed, the land value is the historic cost of land, scaled up by a factor representing the growth in demand for airport services between time 0 and today. This proposal for valuation is in fact very close to the suggestion by the ACCC. A formal derivation of this result is also provided in the Appendix.

A simple analogy assists in understanding our reasoning as to the importance of the constraint on moving the airport. Suppose one day you discover that a longlost relative has left you a castle in Bavaria. Unfortunately, the relative's will stipulates that the castle is only for your direct enjoyment on holidays - it cannot be sold or converted to a hotel or some other use without forfeit. Should you then look to the value of recently sold Bavarian castles to determine how much your inheritance is worth? The answer is generally no. The value to you is constrained by the rule that you are not allowed to sell the castle. Instead, the worth of the castle is precisely how much you value the stream of services that it delivers to you as a holiday destination. This is likely to be lower than its market value. Similarly, the worth of unconvertible land at Sydney Airport should be measured 
by the value that it generates for airport users, and this can be estimated with reference to the demand for such services, calculated, for example, according to how much demand has grown since the airport's inception. The added complication with the airport over the Bavarian castle example is that the land valuation is not an end in itself, but rather it is an input into the price-regulatory process. Despite this, the intuition for the appropriate land valuation is the same.

As an alternative exposition of the model, consider Figure 1. In the figure the horizontal axis shows the quantity of airport land (L). The vertical axis shows 'value' in dollars. The price of land per hectare when the airport was initially established is shown as $p_{0}$ and the price of land today is given by $p_{1}$. The marginal benefit of land used as airport land in the initial period is shown by $\mathrm{MB}_{0}$. A social planner aiming to maximise net benefit would set the airport size at $\mathrm{L}_{0}$, which is determined by the intersection of $\mathrm{MB}_{0}$ with $\mathrm{p}_{0}$ (that is, where $\mathrm{MB}_{0}=\mathrm{p}_{0}$ ).

\section{Figure 1: Optimal allocation of airport land at time 0 and today}

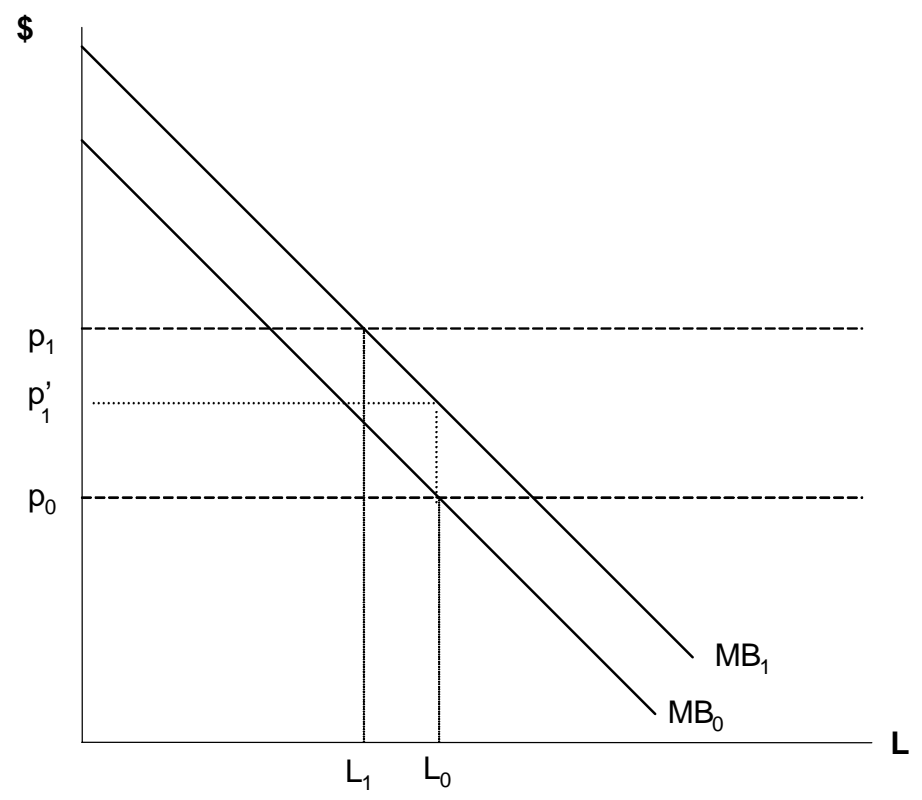

Now consider the optimal airport size at time 1. The marginal benefit of airport land has increased, denoted by the shift of the marginal benefit curve to $\mathrm{MB}_{1}$. The price of land, however, has also risen to $\mathrm{p}_{1}$. The optimal size of the airport if it were to be chosen today would be $\mathrm{L}_{1}$. If it were possible it would be optimal to reduce the airport land size to $\mathrm{L}_{1}$. As we have argued, the size of the airport at date 1 is fixed (in this simple model, it cannot be adjusted at all). Thus the marginal value of airport land today is given by the intersection of $\mathrm{MB}_{1}$ with $\mathrm{L}_{0}$ (equal to $\mathrm{p}_{1}{ }^{\prime}$ ); the value of airport land reflects the growth in demand from $\mathrm{MB}_{0}$ to $\mathrm{MB}_{1}$. If surrounding land prices have risen more than demand for airport services (case shown in Figure 1), this valuation will lie between $p_{0}$ and $p_{1}$ and 
indicates that the ambient value argument overstates the value of airport land. Note that the question to be addressed by the regulator at time 1 is not choosing the optimal airport size at this point in time per se; instead, the regulator today concerned with regulating airport usage fees. It is because the implied land value is an important determinant of aeronautical charges that this analysis is of interest; the ambient value argument is not correct because the airport is fixed in size and that size is larger than what would have been the optimal size if the airport were built at time $1\left(\mathrm{~L}_{0}>\mathrm{L}_{1}\right)$.

\section{Extensions of the Argument}

This section shows that the result of the basic model - that the ambient value is not the correct measure of the opportunity cost of airport land - holds in a wide range of circumstances. For example, the question, arises as to how much of the SACL's land assets are sunk in practice, and hence 'unconvertible'. In reality, it is possible to convert at least some portion of airport land to other uses and to make additional purchases of land. We first extend the model to allow for situations when an airport makes current land purchases. In our second extension, we consider the possibility that the original airport builders perfectly anticipate future airport use. Our conclusion that ambient value overstates true value is unchanged provided that total airport land usage is larger than if the airport were to be built today, although in this modification the ambient value is used as part of the calculation of the true value. The worth of land that is convertible to other uses, however, should reflect ambient value, for the same reason that ambient value is relevant if the entire airport were moved.

In the final extension considered here, we allow for the possibility the airport generates externalities - positive or negative - that affect surrounding land value. Some business might, for example, be attracted to airport sites to take advantage of reduced transportation costs. Roads built near airports can also attract residential development. These represent positive externalities. Negative externalities that tend to reduce surrounding land value might include airport noise and air pollution. It turns out that neither positive nor negative externalities alter the basic conclusion. These complications result in changes in the amount of land used for the airport, not a change to the conclusion that valuing all of the land at ambient value is inappropriate.

\section{Current land purchases}

One objection to our argument could go as follows: Since SACL has purchased new land recently, it must be the case that $\mathrm{L}_{1}>\mathrm{L}_{0}$, and hence the marginal benefit of airport land must be equal the surrounding land price $\mathrm{p}_{1}$. However, adding more realism to the model above easily deals with this objection. The land purchased at time 0 is in reality modified over time with capital and labour inputs, and formed into a new asset that is quite different in character from the original land. Instead, it is airport land - a mixture of runways, land and aprons designed 
to produce airport services. The only crucial factors for the above argument to hold are:

- that the modified 'airport land' that would be built at time 0 would have a larger input of unimproved land than currently, and;

- that airport land is unconvertible in its current location, whether by legislation or for physical reasons.

Thus, any purchases of unimproved land at date 1 are designed to fit in with the unconvertible design of airport land from time 0 . The airport would be very different, or re-located, if it was built today.

\section{Perfect anticipation of future use}

A second potential objection to the basic model is that the builders of the airport at time 0 would have taken into account the future value of the land when they determined the size of the airport. It is easy to show that this does not change the basic proposition that the ambient value argument is incorrect. When planning the size of the airport at time 0, a forward-looking government will take into account future benefits and costs. This is necessary because of the irreversibility of any investment in airport land. The total benefits of airport land are equal to the land's time 0 benefits plus the appropriately discounted future benefits to be derived from airport services. The opportunity cost includes both the time 0 land price $\left(\mathrm{p}_{0}\right)$ and the appropriately discounted price of land at date $1\left(\mathrm{p}_{1}\right)$. If, as above, the price of land is assumed to increase more than the increase in the benefit of airport services, the government will choose an airport size less than the $\mathrm{L}_{0}$ chosen by a myopic social planner (as in the basic model) but greater than the airport size $\mathrm{L}_{1}$ that would have been built if the airport were to be built from scratch today.

This intuition also can be illustrated using Figure 1. Assume that the airport owner has perfect foresight at time 0 and knows that land prices in the area are going to rise at a faster rate than the marginal benefit of airport services. If $\mathrm{L}_{0}$ cannot be reduced in the future, the optimal amount of airport land would lie somewhere in between the solutions to $\mathrm{MB}_{0}=\mathrm{p}_{0}$ and $\mathrm{MB}_{1}=\mathrm{p}_{1}$. Further, if the price of land rises at a faster rate than the benefit from airport services, then the public owner would not want to increase the airport size at time 1. This discussion is formalised in the Appendix (see Proposition 2).

Now consider how a regulator should assess the value of airport land at date 1. From Figure 1, as the airport size is between $\mathrm{L}_{0}$ and $\mathrm{L}_{1}$, the marginal benefit of airport land today is less than the surrounding land price $\mathrm{p}_{1}$. The precise value of airport land depends on the time 0 land price $\mathrm{p}_{0}$, the current land price $\mathrm{p}_{1}$, the growth in demand for airport services and the government's discount factor. Unlike in the basic model above, current land prices do feature in the value of airport land. This is because $\mathrm{p}_{1}$ is anticipated by the social planner at the time the airport was established. The importance of this factor depends on the size of the discount factor between time 0 and date 1 ; the specific relationship is derived in the appendix. However, as in the myopic case, if the growth in land prices is 
greater than the growth in demand for airport services, the value of airport land will be less than the ambient value. Finally, note that if it is possible to recover land at time 1 at some cost per unit, the valuation of land will fall below ambient value reflecting both the cost of recovery and the growth in demand for airport services.

\section{Externalities}

It may be the case that the presence, or even the size, of the airport will affect the value of surrounding land. This externality could be negative if considering the effect of airport noise on the value of residential properties; alternatively, the airport may increase the value of surrounding land used for industrial purposes (see, for example, Burns et al, 2001, Espey and Lopez 2000 and Feitelson, Hurd and Mudge, 1996). We show that the presence of either a negative or a positive externality between the airport and the value of the surrounding land does not affect our basic argument.

Assume that the airport planner is myopic, as in the basic model. In choosing the size of the airport at time 0 the social planner will consider the direct benefit of airport services (as above) as well as the externality. If there is a positive externality, the airport size will be larger than if there were no external benefit. Similarly, the airport will be smaller with a negative externality than otherwise. An equivalent decision would be made at date 1 if the airport were to be built today; the government would take into account any positive or negative externality that airport land generates. In Figure 1, a positive externality could be illustrated by an upward shift of the marginal benefit curves; similarly a negative externality could be shown as a downward shift in the curves.

The presence of any externalities does not, however, alter the irreversibility of the investment in airport land. Thus, if the increase in land price between time 0 and today is more than the growth in demand for airport services, the size of the airport chosen at time 0 will be larger than if the airport were built today. Although the absolute size of the airport might be affected, it is still the case that $\mathrm{L}_{0}>\mathrm{L}_{1}$. Consequently, the marginal benefit of airport services today is less than the current land price, and the ambient value is not the correct valuation for regulatory purposes.

In summary, provided that the airport land is sunk and the growth in prices is greater than the growth in demand for airport services, then $\mathrm{L}_{0}>\mathrm{L}_{1}$ and surrounding land prices do not reflect the marginal value of airport land. The externality, be it positive or negative, simply acts to alter the (optimal) quantity of land devoted to airport uses.

\section{Discussion}

The main purpose of our paper is to present a simple model in order to argue for correct methodology in future regulatory decisions, not simply to argue for particular dollar figure for land valuation, or even to insist that ambient value will 
always be inappropriate. The development of a simple model gives the argument a sound technical basis that may be used as a step towards reducing the confusion surrounding the valuation issue. It is hoped that this will serve as a starting point for examining other important issues. We do not consider, for example, the issue of landing slot allocations. Similarly, our simple model assumes, purely for expositional purposes, that there is no peak demand problem at Sydney airport.

Although Sydney Airport is subject to congestion, allowing excessive land valuation is an indirect method of dealing with the problem based on an incorrect methodology. Our methodology, based on using demand information, implies that a more market-orientated landing fee system such as peak-load pricing is appropriate. Currently, the SACL uses a weight-based charging system for aeronautical services. These charges act as Ramsay prices, minimising the reduction in demand and charging different users different prices (Forsyth, 2001:15). A more appropriate system would be a per-landing fee. Currently, a jumbo jet pays vastly more for landing rights than, for example, a regional propeller-driven aeroplane, even though the latter actually imposes greater congestion costs due to its slower manoeuvring.

A further qualification arises in the presence of peak and off-peak demand. The SACL may wish to expand the airport to deal with peak demand. In this case the ambient value at the time of purchase is an approximation of the valuation for that additional land. However, since the airport is not always congested, and the airport does not charge peak-load prices, an estimation of Sydney Airport land valuation must reflect a weighted average of ambient and off-peak-demand valued land. This valuation will necessarily be less than the ambient value. It is only when the airport is always congested that the ambient value will be correct.

The model presented in this paper raises several other issues worth discussing. First, the Productivity Commission's (2002:410) reasoning that ambient value is appropriate for the purpose of regulation, in order that correct incentives be given for re-location decisions, is at best confusing. Why use the incorrect methodology for regulation when the decision about moving can be made separately with reference to the ambient value? In the unlikely event that removal of the airport is considered in the near future, ambient value is a relevant input into any cost-benefit calculations, because moving the airport actually will result in sale of the land and its transfer into the hands of people with valuations similar to ambient value, much as would happen if a beneficiary was allowed to sell the inherited Bavarian castle in the illustrative analogy provided in the section on the basic model above. And even in this case the relocation costs of the airport and associated facilities would need to be included in any valuation. However, applying the incorrect methodology to the task of valuing the airport for the purpose of regulation only serves to create confusion in the regulatory process in the future.

Second, a similar argument can be made with reference to price discrimination and efficient rent extraction. The airport operator, given its monopoly position, may well have the ability to engage in price discrimination. These higher rents could be transferred to the government via a higher sale price 
for the airport, for example. By its very nature, price discrimination is about the structure of prices, and this is not directly affected by the level of the land valuation. Consequently, a higher land valuation for the purposes of setting a price cap does not directly aid price discrimination, and the efficient capturing of surplus. In other words, if rent extraction is the objective of the government using an incorrect measure for land assets is an indirect, and most likely ineffective, method of achieving this goal.

Last, our model demonstrates that reference to demand for airport services is precisely the piece of information necessary to remove the so-called 'circularity problem', mentioned by Professor Kahn (in the introduction) and the cause of much concern to regulators. The circularity problem is the following puzzle: How can we value land for regulatory purposes when regulation itself affects the value of land? The puzzle only arises because practitioners do not use a vital piece of information in their calculations, namely demand for airport services. The value of sunk airport land is precisely the (estimated) shadow value of land as determined by (estimated) demand for airport services that are subject to regulatory constraints. The resolution of the circularity problem is relevant to regulation of airports more generally: for example, the Melbourne, Brisbane, Perth, Adelaide, Canberra, Darwin, Hobart, Launceston, Coolangatta, Townsville and Alice Springs airports were all subject to price-cap regulation until 30 June 2002.

\section{Concluding comments}

We argue for a methodology that uses demand for airport services, information that is missing from other analyses. Using this methodology, we argue that current land prices are not the appropriate measure of the value of airport land. Airport land is sunk in its current location so that the current price of surrounding land does not reflect a forgone opportunity. Instead, the marginal value of airport land can be approximated using demand estimates. For example, value could be estimated by the price of land at the time the airport was built, scaled up by a factor reflecting the increase in the benefits of the airport over that time. This conclusion holds for a wide range of possible extensions provided that: (a) the land used in the airport is larger than if the airport was constructed today; and (b) the airport is sunk in its current location.

Finally, our model also illustrates how demand can be used to overcome the circularity problem. Demand for airport services provides information regarding the shadow value of airport land. This information breaks the supposed connection between the regulator's valuation of the asset base and the prices that can be charged. 


\section{Appendix}

\section{The basic model}

$\mathrm{L}_{0}$ denotes the amount of land used by the airport at 'time 0 ' when the airport was substantively established, and $\mathrm{L}_{1}$ is the socially optimal amount of land today — at 'date 1'. The price of land at time 0 was $\mathrm{p}_{0}$ and the price of land today is $\mathrm{p}_{1}$. The airport delivers increasing and strictly concave benefit $\mathrm{B}_{0}\left(\mathrm{~L}_{0}\right)$ at time 0 , and $\mathrm{B}_{1}\left(\mathrm{~L}_{1}\right)$ today. The public-owned airport at time 0 was built under a myopic objective to maximise the net value to users of the airport based on price $\mathrm{p}_{0}$. At time $0, \mathrm{~L}_{0}$ is chosen to maximise

$$
\mathrm{B}_{0}\left(\mathrm{~L}_{0}\right)-\mathrm{p}_{0} \cdot \mathrm{L}_{0}
$$

which yields

$$
\mathrm{B}_{0}{ }^{\prime}\left(\mathrm{L}_{0}\right)=\mathrm{p}_{0} \text {. }
$$

Assuming $\mathrm{B}_{0}{ }^{\prime} \geq \mathrm{p}_{0}$ ensures an interior solution.

Suppose that $\mathrm{L}_{0}$ cannot be reduced for reasons argued above. Were the airport built today, the public owners would choose $\mathrm{L}_{1}$ to maximise

$$
\begin{aligned}
& \mathrm{B}_{1}\left(\mathrm{~L}_{1}\right)-\mathrm{p}_{1} \cdot \mathrm{L}_{1} \text {, subject to } \mathrm{L}_{1} \geq 0 \text {, which yields } \\
& \mathrm{L}_{1}\left[\mathrm{~B}_{1}{ }^{\prime}\left(\mathrm{L}_{1}\right)-\mathrm{p}_{1}\right]=0, \quad \mathrm{~L}_{1} \geq 0, \quad\left[\mathrm{~B}_{1}{ }^{\prime}\left(\mathrm{L}_{1}\right)-\mathrm{p}_{1}\right] \geq 0 .
\end{aligned}
$$

The Kuhn-Tucker (KT) conditions represent the fact that if the airport were to be newly built today it would be possible to set $\mathrm{L}_{1}=0$.

Let $B_{1}(L)=\beta \cdot B_{0}(L)$ where $\beta>1$ represents the growth in demand for airport services. The constraint in (3) is binding if $B^{\prime}(0)>p_{1}$. For this case (3) becomes $\beta B_{0}{ }^{\prime}\left(L_{1}\right)=p_{1}$. Let $p_{1}=\pi p_{0}$, where $\pi$ is the growth in land price. The equation defining $L_{1}$ becomes

$\mathrm{B}_{0}{ }^{\prime}\left(\mathrm{L}_{1}\right)=(\pi / \beta) \cdot \mathrm{p}_{0}$,

and the factor $\pi / \beta$ represents the growth in surrounding land value prices relative to the growth in demand for airport services. This yields the following proposition:

\section{Proposition 1}

$$
\text { If } \pi>\beta \text {, then } \mathrm{L}_{1}<\mathrm{L}_{0} .
$$

If we accept that $\mathrm{L}_{1}<\mathrm{L}_{0}$, then the marginal value of land today is given by the original choice of land $\mathrm{L}_{0}$ along with the function $\mathrm{B}_{0}$ ' and the growth factor $\beta$, due to our assumption that this land is sunk in its current location. Thus the appropriate marginal value of land is $\mathrm{B}_{1}{ }^{\prime}\left(\mathrm{L}_{0}\right)=\beta \mathrm{B}_{0}{ }^{\prime}\left(\mathrm{L}_{0}\right)=\beta \mathrm{p}_{0}$ using equation (2). Assuming $\beta<\pi$, we have current per-unit land value $\beta \mathrm{p}_{0}<\mathrm{p}_{1}$, and the ambient value argument is incorrect. 


\section{Perfect Anticipation of Future Use}

When the future value of the land is taken into account, the building of the airport at time 0 will reflect choices with respect to $\mathrm{L}_{0}$ and $l_{1}$ so as to maximise

$$
\left[\delta \mathrm{B}_{1}\left(\mathrm{~L}_{0}+l_{1}\right)+\mathrm{B}_{0}\left(\mathrm{~L}_{0}\right)-\delta \mathrm{p}_{1} l_{1}-\left(\mathrm{p}_{0}+\delta \mathrm{p}_{1}\right) \mathrm{L}_{0}\right],
$$

where $l_{1} \geq 0$ is the addition to time 0 land at time $1, \mathrm{~L}_{0}$ (as before) is the time 0 choice, sunk at date 1 , and $\delta<1$ is the discount factor on future benefits seen from time 1 . We will assume that $\mathrm{B}_{\mathrm{t}}{ }^{\prime}(0)=\infty$ to rule out corner solutions $\mathrm{L}_{0}=0$. The opportunity cost of land at time 0 is $\mathrm{p}_{0}+\delta \mathrm{p}_{1}$.

The solution to this problem is given by the following two conditions

$$
l_{1}\left[\mathrm{~B}_{1}{ }^{\prime}\left(\mathrm{L}_{0}+l_{1}\right)-\mathrm{p}_{1}\right]=0, \quad l_{1} \geq 0, \quad\left[\mathrm{~B}_{1}{ }^{\prime}\left(\mathrm{L}_{0}+l_{1}\right)-\mathrm{p}_{1}\right] \geq 0
$$

and

$$
\delta \mathrm{B}_{1}{ }^{\prime}\left(\mathrm{L}_{0}+l_{1}\right)+\mathrm{B}_{0}{ }^{\prime}\left(\mathrm{L}_{0}\right)=\mathrm{p}_{0}+\delta \mathrm{p}_{1} .
$$
gives

Substituting $B_{1}(L)=\beta \cdot B_{0}(L)$, and $p_{1}=\pi p_{0}$ into the KT conditions above

$$
\mathrm{B}_{0}{ }^{\prime}\left(\mathrm{L}_{0}+l_{1}\right) \leq(\pi / \beta) \mathrm{p}_{0}
$$

This yields the following proposition:

Proposition 2:

$$
\text { Suppose } \beta<\pi \text {. Then } l_{1}=0 \text {. }
$$

Proof: Suppose this is not the case and $l_{1}>0$. The first order condition will then hold with equality, so that $\mathrm{B}_{0}{ }^{\prime}\left(\mathrm{L}_{0}+l_{1}\right)=(\pi / \beta) \mathrm{p}_{0}$. Substitution of this expression and $\mathrm{p}_{1}=\pi \mathrm{p}_{0}$ into the second of the first-order conditions yields

$\mathrm{B}_{0}{ }^{\prime}\left(\mathrm{L}_{0}\right)=[1+\delta \pi-(\delta \pi) / \beta] \mathrm{p}_{0}<(\pi / \beta) \mathrm{p}_{0}$ because $\pi>\beta$.

Combining these gives $\mathrm{B}_{0}{ }^{\prime}\left(\mathrm{L}_{0}+l_{1}\right)>\mathrm{B}_{0}{ }^{\prime}\left(\mathrm{L}_{0}\right)$, a contradiction.

We are now in a position to calculate the value of land at date 1 . Using $l_{1}=0$, from the proof above, we get

$$
\mathrm{B}_{1}{ }^{\prime}\left(\mathrm{L}_{0}\right)=\beta \mathrm{B}_{0}{ }^{\prime}\left(\mathrm{L}_{0}\right)=(1+\delta \pi) /(1+\delta \beta) \cdot \mathrm{p}_{0}<\pi / \beta \mathrm{p}_{0}<\mathrm{p}_{1}
$$

From this, land valuation is some mark-up of historic cost $p_{0}$. The main difference in this case is that there is a component $\pi$ in the pricing mark-up formula $(1+\delta \pi) /(1+\delta \beta)$ that does reflect current land value to some extent. As an example (not intended to reflect reality) if the growth in land price was double the 
growth in value of airport services $(\pi=2 \beta)$, then from the formula above says the value of airport land lies in between the historic cost of land, and twice this value.

\section{References}

Australian Competition and Consumer Commission (2000), 'Infrastructure Industries: Aviation', ACCC, Melbourne, available from: http://www.accc.gov.au/content/index.phtml/itemId/467185.

Australian Competition and Consumer Commission (2001), 'Sydney Airports Corporation Ltd.: Aeronautical Pricing Proposal: Decision', May.

Burns, M, V. Kupke, W. Marano and P. Rossini (2001), 'The Changing Impact of Noise and Airport Proximity on Residential Property Values', Paper Presented at the Industry Economics Conference, University of Melbourne, July 12-13.

Espey, M. and H. Lopez (2000), 'The Impact of Airport Noise and Proximity on Residential Property Values', Growth and Change 31(3):408-19.

Feitelson, E., R. Hurd and R. Mudge (1996), 'The Impact of Airport Noise on Willingness to Pay for Residences', Transportation Research Part D: Transport and Environment $1(1): 1-14$.

Forsyth, P. (1997), 'Price Regulation of Airports: Principles with Australian Applications', Transportation Research Part E: Logistics and Transportation Review 33(4):297-309.

Forsyth, P. (2001), 'Privatisation and Regulation of Australian and New Zealand Airports', Paper Presented at the Industry Economics Conference, University of Melbourne, July 1213.

Hooper, P., R. Cain and S. White (2000), 'The Privatisation of Australia's Airports', Transportation Research Part E: Logistics and Transportation Review 36(3):181-204.

Kahn, A. (2001), 'Evidence of Alfred E. Kahn On Behalf of Sydney Airports Corporation', National Economic Research Associates mimeo, January 17, 2001.

Productivity Commission (2001), Price Regulation of Airport Services, Report no. 19, AusInfo, Canberra.

The authors would like to thank Katrina Dukats, Peter Forsyth, Stephen King, Vladimir Smirnov and, in particular, an anonymous referee and the editor Franco Papandrea for their helpful comments. Some of the ideas in this paper emerged as part of a consultancy provided by Pitchford to the ACCC. The authors are solely responsible for any errors. 